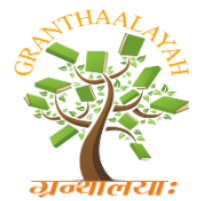

\author{
INTERNATIONAL JOURNAL OF R
GRANTHAALAYAH \\ A knowledge Repository
}

Social

\title{
EFFECTIVENESS OF FLIPPED CLASSROOM LEARNING IN THE ACHIEVEMENT OF COMPUTER SCIENCE AMONG HIGHER SECONDARY SCHOOL STUDENTS
}

\author{
R. Latha ${ }^{* 1}$, Dr. N. Ramakrishnan ${ }^{2}$ \\ ${ }^{* 1}$ Research Scholar (Part-Time) Professor and Head Tamil Nadu Teachers Education University, \\ Karapakkam, Chennai - 97, India \\ ${ }^{2}$ Department of Educational Technology, Tamil Nadu Teachers Education University, \\ Karapakkam, Chennai - 97, India
}

\begin{abstract}
Modern Techniques are introduced in teaching and learning process frequently one such technique is Flipped Classroom learning. Where the pupils are asked to learn the contents given to them at their home from the available sources and they review the topics in their classroom. Since every student collect information from various sources like YouTube, Video lessons, different types of educational apps, Magazines and sources from elders etc. the collection will be excellent to review and collective ideas can help them to learn better than routine blackboard chalk and talk method by doing. So, they learn effectively and their doubts are cleared through discussion with peers in the presence of teacher. The teacher can conclude the teaching learning process by giving extra information left untouched by the students. The researcher is a computer science teacher so she took a lesson from Eleventh Standard Computer Science text book of State board in the 4th Chapter of Volume - I, "Theoretical Concepts of Operating System" and she prepared a video lesson, that video lesson is utilized by the students to learn the contents allotted to them. The Conclusion of her studying, she found that flipped classroom learning is effectively impact in the course content to the students.
\end{abstract}

Keywords: Flipped Classroom Learning; Effectiveness; Achievement of Computer Science.

Cite This Article: R. Latha, and Dr. N. Ramakrishnan. (2019). "EFFECTIVENESS OF FLIPPED CLASSROOM LEARNING IN THE ACHIEVEMENT OF COMPUTER SCIENCE AMONG HIGHER SECONDARY SCHOOL STUDENTS." International Journal of Research Granthaalayah, 7(10), 452-457. https://doi.org/10.29121/granthaalayah.v7.i10.2019.541.

\section{Introduction}

Every teacher likes to make his or her class child oriented. They make effortless work to achieve this. Now a days most of the students are familiar with internet access either through their laptops or personal computers. Atleast many of them are using cell phones to access internet. So, they 
can easily flip their studies through various educational apps and websites. So the teachers have to guide their pupils to use all the available sources to undergo their flipping at their homes. Therefore, teachers are optimistic with these kind of new trends in the teaching and learning process.

\section{Need for the Study}

In the past, students attended their classes without any prior preparation. All the subject matters they have got through the lecture method by their teachers. Hardly they got homeworks. Now flipping reversed it. The new trend made the child to do some homework on the next day topic. Various children doing in different ways which help everyone to learn in a better way. This study actually identifying the goodness of flipped classrooms and recommending to the modern newage teachers to undergo most interesting classroom activities.

"Technology in the twenty-first century puts instantaneous access to information, and the Internet can be handily accessed through numerous technology tools such as laptop, computer, and Smartphone"(Fu, 2013). "Now more than ever, students spend much of their waking time on using some sort of technology tools by using technology, it is possible for them to interact with friends, instructors, and learning content everywhere, not only in the class but also outside the class through distance learning "(Fisher, 2009). Richter and McPherson ,2012 conclude that "In today's digital age, every student can access many free Internet learning resources such as online video lectures and they can watch these free contents everywhere and at their convenience". "Even more, the use of the traditional learning approach which focuses on the instructor as the center of knowledge is irrelevant in today's digital age" (Wang \& Heffernan, 2010).

\section{Definitions of Terms Used in This Study}

Flipped Classroom - This is a new instructional strategy that reverse the regular traditional method of classroom by delivering some new technology based instructional content, online video lessons and outside the classroom activities. A flipped classroom learning is students get their content knowledge at their home and practice them in their classroom with the help of peers and teachers.

Effectiveness - refers to produce a desired output or result.

Achievement in Computer Science - refers to reach the objectives of the content knowledge in Computer Science as a subject among Higher Secondary School Students.

\section{Objectives of This Study}

The following objectives are attempted in this present study:

1) To create a video lesson from XI Standard Computer Science textbook, Volume-I, Unit-I, Chapter 4 and the topic of the lesson is "Theoretical concepts of Operating System".

2) To validate the video lesson from XI Standard Computer Science textbook, Volume-I, Unit-I, Chapter 4 and the topic of the lesson is "Theoretical concepts of Operating System". 
3) The investigator identified the teaching points for the Theoretical concepts of Operating System which is in Volume-I, Unit-I, Chapter 4 of XI Standard Computer Science textbook in Tamil Nadu State Board syllabus following English Medium.

4) The investigator presented the teaching point to the computer science lecturers and post graduate computer science teachers working in higher secondary schools and they were appraised about the purpose of the experiment. The experts verified and reviewed the teaching points. This ensure content validity and face validity of the items in the package.

\section{Hypothesis for This Present Study}

The following hypothesis are framed by the investigator for her present study.

H1. From the mean score there is no significance difference on Criterion Test on Theoretical concepts of Operating System which is in Volume-I, Unit-I, Chapter 4 of XI Standard Computer Science textbook in Tamil Nadu State Board syllabus following English Medium between Pre-test and Post-test of experimental group design.

\section{Limitations of This Study}

This present study is conducted for the Flipped Classroom module created and validated on Theoretical concepts of Operating System which is in Volume-I, Unit-I, Chapter 4 of XI Standard Computer Science textbook in Tamil Nadu State Board syllabus. This study is only for XI Std students following Tamil Nadu State Board Syllabus.

This experimental research is conducted only for the urban area students. The other board of XI standard CBSE, ICSE and other streams have not been considered for this present study. English Medium syllabus of Tamil Nadu Textbook Society for XI Standard computer science has been taken for this study.

\section{Methodology - Design of The Study}

Design of this present study is the set of methods and rules used in collecting and analyzing measures of the variables specified in the problem research. In the present study, the researcher creating and validating flipped classroom on "Theoretical concepts of Operating System" which is in Volume-I, Unit-I, Chapter 4 of XI Standard Computer Science textbook in Tamil Nadu State Board syllabus. To achieve the objectives, the researcher has selected a Pre-test and Post-test experimental group design. The schematic presentation of the design for this study is as follows:

\begin{tabular}{|l|l|}
\hline \multicolumn{2}{|c|}{ Pre test - Post test Experimental design } \\
\hline \multicolumn{2}{|c|}{ I. VARIABLES } \\
\hline 1. Independent Variable & $\begin{array}{l}\text { Flipped classroom in the Theoretical concept } \\
\text { of Operating System in Computer Science } \\
\text { Unit of XI std through Video Lesson for } \\
\text { Flipped Module in Experimental Group. }\end{array}$ \\
\hline 2. Dependent Variable & $\begin{array}{l}\text { Criterion Test in Theoretical concept of } \\
\text { Operating System in XI std Computer Science } \\
\text { syllabus. }\end{array}$ \\
\hline
\end{tabular}




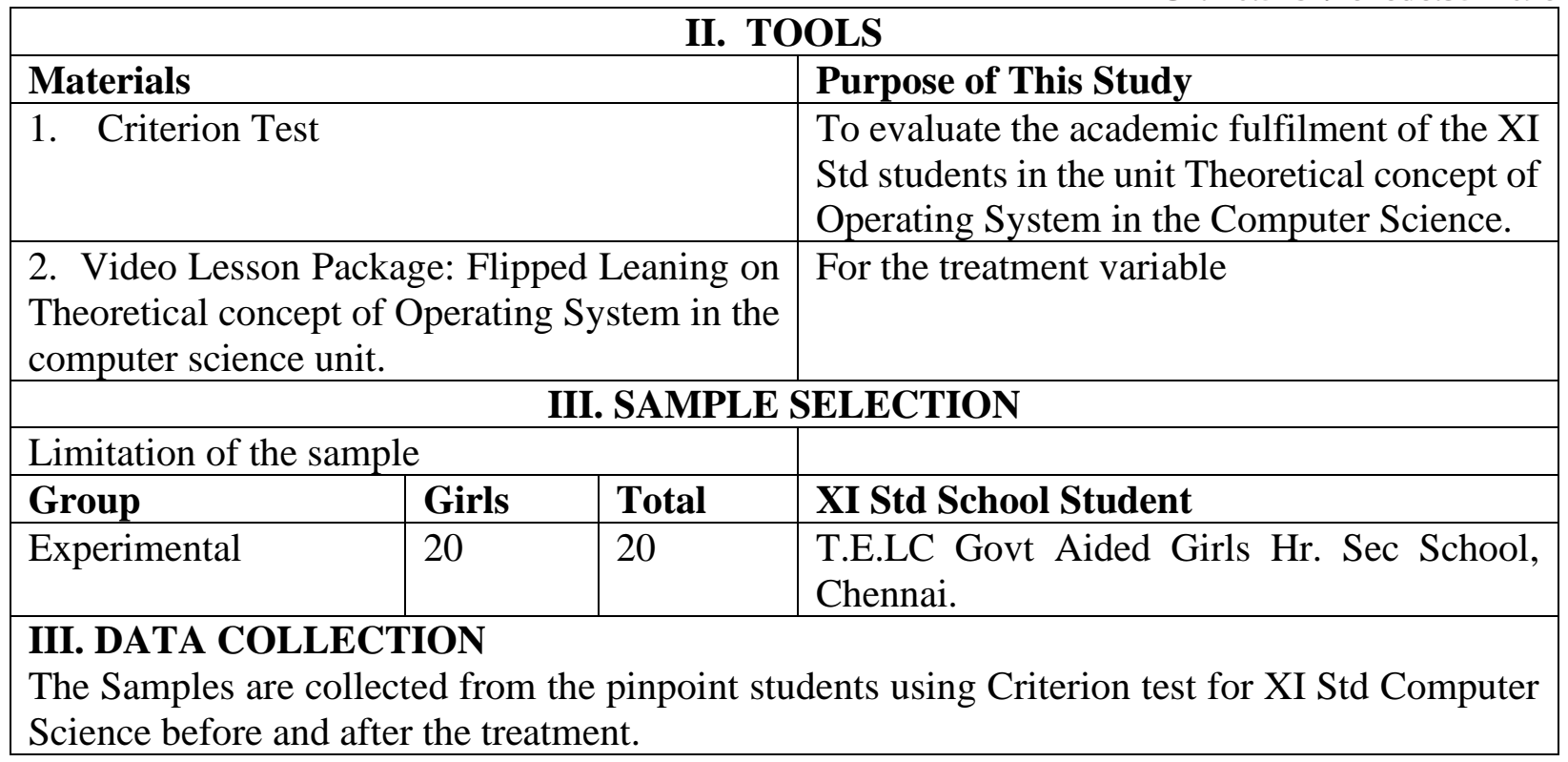

\section{Item Analysis for The Criterion Test}

To improve the validity and reliability of the test usually we go for the Item analysis. From that item analysis we have to find the item difficulty level and item discriminative index level.

\section{Data Collection}

The present study is a Pre- test and Post- test Experimental Group design. The selected sample for conducting the experiment is presented in the above table.

\section{Data Analysis}

The researcher applied ' $t$ ' test between Pre- test and Post- test scores of Criterion Test in Theoretical concept of Operating System in the XI Standard Computer Science Syllabus.

\section{Hypothesis - I}

There is no significance difference between the mean scores of Criterion Test on Theoretical concept of Operating System in the Computer Science Unit between Pre- test and Post- test of experimental group of XI std students.

The following table shows that the 't' test results on the Criterion Test in Theoretical concept of Operating System in the Computer Science Unit between Pre- test and Post- test of experimental group.

Criterion Test in Theoretical concept of Operating System in Computer Science between Pre- test and Post- test of Experimental Group

\begin{tabular}{|c|l|l|l|l|l|l|}
\hline \multicolumn{1}{|c|}{ Test } & $\begin{array}{c}\text { Total No. of the student } \\
\text { N }\end{array}$ & Mean Score & SD & 't' & DF & Significant Level \\
\cline { 1 - 5 } Pre Test & 20 & 41 & 7.9 & $\mathbf{2 . 4 4 6}$ & 38 & 0.01 \\
\hline Post Test & 20 & 46 & 5.2 & & & \\
\hline
\end{tabular}


From the above table the ' $\mathrm{t}$ ' value between the Pre- test and Post- test of Experimental group in the Criterion Test in Theoretical concept of Operating System in the Computer Science is 2.446. It is significant at 0.01 and 0.05 level for the $\mathrm{df}$ 38. The mean of Post test of Experimental group (46) is higher than the mean of Pre test of Experimental group (41). Therefore, the research hypothesis is accepted and null hypothesis is rejected. This could be inferred that the Flipped Classroom in theoretical concept of Operating System in the Computer Science chapter has positively had an impact in the XI Standard students' academic achievement in Computer Science Subject.

\section{Effectiveness of Flipped Classroom}

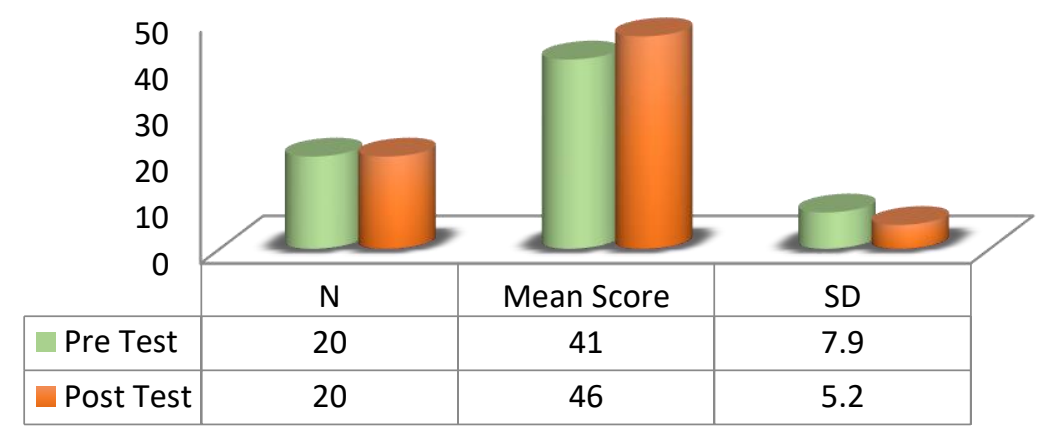

The above Picture shows that the Significance Difference in the Mean Achievement of Criterion Test in Theoretical concept of Operating System in Computer Science between Pre-Test and PostTest of Experimental Group.

\section{Finding of This Study}

The Flipped Classroom in Computer Science Unit has had a positive impact on XI Standard Students' Achievement in Computer Science Subject.

\section{Conclusion}

The Flipped Classroom is proposed as an effective instructional approach. In fact, it is very compatible with most of our commonly accepted practices of learning theory. As far as the overall effectiveness of the pedagogical subject, this present study conclude that the experiment study has been conducted for XI Std Computer Science Students before and after flipped instruction. Derived from this experiment, the researcher concluded that the students' academic fulfilment has had a high impact positively after the Flipped Classroom activities in computer science unit of XI std students.

\section{Educational Implication}

The present study indicates that the Flipped Classroom has impacted positively in students' academic achievement in computer science subject. Therefore, all the computer science teachers may use this instruction strategy for their subject. The student may learn the concepts easily from 
the video lesson. All the schools and other educational institutions may continue to implement technology-based learning as it will provide the effective teaching and learning for all the pupils.

\section{References}

[1] Fezile Ozdamli, (20 July 2016), "Flipped Classroom Approach", World Journal on Educational Technology, Vol 8, Issue 2, (2016) 98-105.

[2] Ramakrishnan et. al., Vol.4 (Iss.10: SE): October,2016, "Effectiveness of Flipped Classroom in Mathematics Teaching".

[3] Malek Jdaitawi (July 2019), " The Effect of Flipped Classroom Strategy on Students Learning Outcomes", International Journal of Instruction, Vol.12, No.3

[4] The flip: Turning a classroom upside down, Washington Post, 4. June, 2012.

[5] Abeysekera, Lakmal, and Phillip Dawson (2015). "Motivation and cognitive load in the flipped classroom: definition, rationale and a call for research." Higher Education Research \& Development 34(1), 1-14.

[6] Marco Ronchetti (June 2010), "Using video lectures to make teaching more interactive", International Journal of Emerging Technologies in Learning (iJET).

*Corresponding author.

E-mail address: lathabala96@ gmail.com 